\title{
Analysis of Taipei Basin Response for Earthquakes of Various Depths and Locations Using Empirical Data
}

\author{
Vladimir Sokolov ${ }^{1,}$, Kuo-Liang Wen ${ }^{2}$, Joachim Miksat ${ }^{1}$, \\ Friedemann Wenzel ${ }^{1}$, and Chun-Te Chen ${ }^{2}$ \\ ${ }^{1}$ Geophysical Institute, Karlsruhe University, Karlsruhe 76187, Germany \\ ${ }^{2}$ Institute of Geophysics, National Central University, Jhongli, Taiwan, ROC
}

Received 26 May 2008, accepted 15 October 2008

\begin{abstract}
The response of Taipei basin upon earthquake excitation was studied using records of recent earthquakes. The strong-motion database includes records obtained at 32 stations of the Taipei TSMIP network from 83 deep and 142 shallow earthquakes $(M>4.0)$ that occurred in 1992 - 2004. The characteristics of frequency-dependent site response were obtained as spectral ratios between the actual earthquake records (horizontal components) and those modelled for a hypothetical Very Hard Rock (VHR) condition. The models for VHR spectra of Taiwan earthquakes had been recently proposed by Sokolov et al. (2005b, 2006). Analysis of site response characteristics and comparison with simple 1D models of the soil column resulted in the following conclusions: (1) The spectral ratios throughout the basin obtained from deep earthquakes (depth $>35 \mathrm{~km}$ ) exhibit good agreement with the theoretical ratios calculated using the 1D models constructed using available geological and geotechnical data. (2) The spectral ratios obtained from shallow earthquakes show influence of: (a) surface waves generated when travelling from distant sources to the basin and (b) relatively low-frequency $(<1-2 \mathrm{~Hz})$ waves generated within the basin. (3) Some shallow earthquakes produce extremely high amplification at frequencies $0.3-1 \mathrm{~Hz}$ within the basin that may be dangerous for high-rise buildings and highway bridges. (4) The obtained results may be used in probabilistic seismic microzonation of the basin when many possible earthquakes located at various distances are considered. 2D and 3D simulation is necessary to model the seismic influence from particularly large earthquakes.
\end{abstract}

Key words: Site effect, Taipei basin, Deep and shallow earthquakes

Citation: Sokolov, V., K. L. Wen, J. Miksat, F. Wenzel, and C. T. Chen, 2009: Analysis of Taipei basin response for earthquakes of various depths and locations using empirical data. Terr. Atmos. Ocean. Sci., 20, 687-702, doi: 10.3319/TAO.2008.10.15.01(T)

\section{INTRODUCTION}

Seismicity in the Taiwan area is very high, and many large earthquakes $(\mathrm{M}>6.5)$ have occurred in the region in historical and modern times. Some of these earthquakes, e.g., the recent Chi-Chi earthquake of 21 September 1999, caused severe damage. Taipei City is the capital of Taiwan and is located on a sediment-filled basin in the northern part of the island. The area has experienced several damaging earthquakes, the most recent of which occurred on 31 March 2002. The results of previous research on earthquake ground motion peculiarities in the Taipei basin (e.g., Kuo et al. 1995; Wen et al. 1995; Loh et al. 1998; Wen and Peng 1998a, b; Sokolov and Jean 2002; Wang and Lee 2002; Chen 2003;

\footnotetext{
* Corresponding author

E-mail:Vladimir:Sokolov@gpi.uni-karlsruhe.de
}

Fletcher and Wen 2005) showed that large lateral variations in ground-motion characteristics (peak ground acceleration, response spectra, dominant frequencies, etc.) are apparent.

Recent needs of earthquake engineering require consideration of site effect in seismic hazard analysis. When applying the probabilistic approach for seismic hazard estimation in urban territories, it is necessary to take into account the following:

1. Extended areas covered by large cities are characterized by variety of local geological and geotechnical conditions.

2. Different engineering structures (buildings, bridges, lifelines, etc.) require consideration of different parameters 
of ground motion within a relatively broad frequency range of motion.

3. Optimization of engineering decisions demands estimation of ground motion parameters for different return periods (probabilities of being exceeded) concerning structures of different importance factors.

4. Consideration of various recurrence intervals and a broad frequency range of ground motion cause the necessity to cover the influence of different earthquakes that may occur in different seismogenic zones.

In this study we analyzed records of recent earthquakes to explore frequency-dependent response of the Taipei basin. The strong-motion database includes records obtained at 32 stations of the Taipei network from 83 deep and 142 shallow earthquakes $\left(\mathrm{M}_{\mathrm{L}}>4.0\right)$ that occurred in the period, 1992 - 2004 (Fig. 1). Most of the selected stations cover evenly the territory of the basin. In addition, we also consider two stations located outside the basin (TAP053 and TAP071). Table 1 summarize the information about the strong-motion database.

\section{THE TECHNIQUE}

For estimation of the site response from earthquake records it is necessary to remove the source and propagation path effects. Various techniques for site-response estimation, which use the S-wave window, have already been developed and studied (e.g., Bard 1995). The most common procedure (Borcherdt 1970) for the estimation of the site response from earthquake data is to determine the sedimentto-bedrock ratio by dividing the Fourier spectrum of a site by that of a nearby reference (rock) site using earthquake records. However, in many cases, including the Taipei basin, it is difficult to find a station that can be defined, undoubtedly, as a "hard-rock reference" station. There are a few strongmotion bore-hole array sites within the Taipei Basin (Wang 2008). Bottom stations from some of these arrays may be considered as "reference hard rock sites". However, the array due to technical reasons does not accumulate enough records.

Alternative methods not requiring a reference site have been developed recently. One of them involves dividing the horizontal-component shear-wave spectra at each site by the vertical component spectra observed simultaneously at that site (Lermo and Chavez-Garcia 1993). The H/V technique, as has been shown recently by many authors (e.g., Field and Jacob 1995; Theodulidis and Bard 1995; Theodulidis et al. 1996; Bonilla et al. 1997; Castro et al. 1997; Chen and Atkinson 2002; Huang et al. 2002; Siddiqqi and Atkinson 2002; Mucciarelli et al. 2003; Sokolov et al. 2005a, 2007), provides results that are consistent with the general geological conditions of the recording sites, i.e., showing the fundamental frequency of site amplification. The results of the application of the $\mathrm{H} / \mathrm{V}$ technique, however, are affected by local and subsurface factors influencing the vertical component of ground motion. Among the factors we can mention, for example, the following: (a) contribution of compressional deformation (P-wave) to vertical component at frequencies more than $8-10 \mathrm{~Hz}$ (Beresnev et al. 2002); $\mathrm{P}$-wave conversion from the $\mathrm{SV}$-waves at the boundaries of the layers above the base rock (e.g., Takahashi et al. 1992); increase of amplitudes at vertical component due to nonlinear effects in granular materials (Loukachev et al. 2002). Such effects may be minimized by using data only from rock stations (e.g., Chen and Atkinson 2002; Sokolov et al. 2005a, 2007).

It was proposed recently (Sokolov 1998; Sokolov et al. 2000) to use so-called "very hard rock" (VHR) spectral model to estimate site response characteristics in terms of frequency-dependent amplification (spectral ratios). The approach consists of calculation spectral ratios between the actual earthquake records (horizontal components) and the spectra modelled for a hypothetical VHR condition. On the one hand, besides local site response, the spectral ratios

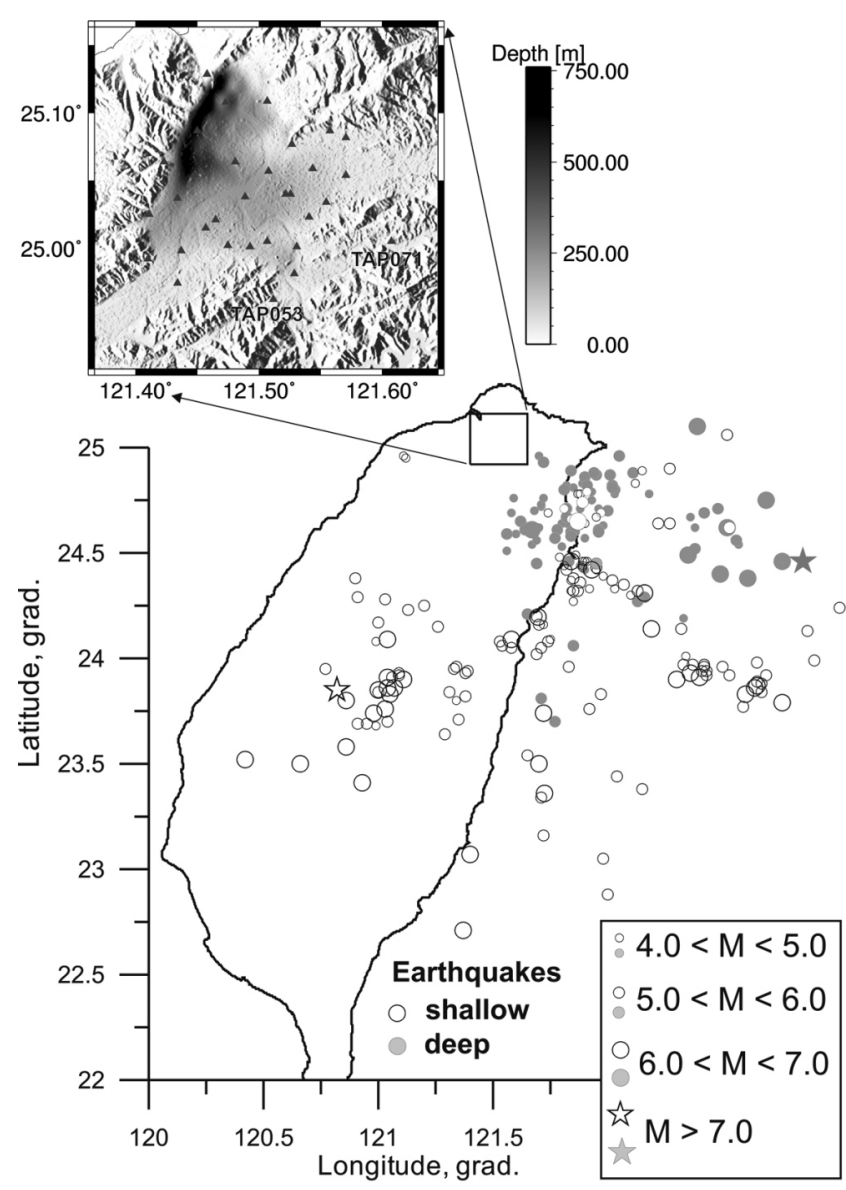

Fig. 1. Distribution of epicentres of earthquakes used in this study (open circles - shallow events, grey circles - deep events) and location of the considered stations (triangles) within the Taipei basin. The depth of Quaternary sediments is also shown in gradations of grey. 
Table 1. Characteristics of the used strong-motion database.

\begin{tabular}{|c|c|c|c|c|c|}
\hline \multirow{2}{*}{ Station } & \multicolumn{2}{|c|}{ Location } & \multirow{2}{*}{ Soil class } & \multicolumn{2}{|c|}{ Number of earthquakes } \\
\hline & Lat., $\mathbf{N}$ & Lon., E & & shallow & deep \\
\hline TAP001 & 25.04 & 121.52 & $\mathrm{E}$ & 18 & 16 \\
\hline TAP002 & 25.13 & 121.45 & $\mathrm{D}$ & 28 & 32 \\
\hline TAP003 & 25.09 & 121.45 & $\mathrm{E}$ & 40 & 11 \\
\hline TAP004 & 25.11 & 121.47 & $\mathrm{E}$ & 14 & 6 \\
\hline TAP005 & 25.11 & 121.51 & $\mathrm{E}$ & 42 & 20 \\
\hline TAP008 & 25.08 & 121.53 & $\mathrm{E}$ & 47 & 24 \\
\hline TAP009 & 25.08 & 121.57 & $\mathrm{E}$ & 34 & 24 \\
\hline TAP010 & 25.06 & 121.48 & $\mathrm{E}$ & 34 & 15 \\
\hline TAP012 & 25.06 & 121.51 & $\mathrm{E}$ & 37 & 27 \\
\hline TAP014 & 25.06 & 121.53 & $\mathrm{E}$ & 48 & 26 \\
\hline TAP015 & 25.05 & 121.57 & $\mathrm{E}$ & 32 & 23 \\
\hline TAP016 & 25.06 & 121.42 & $\mathrm{E}$ & 31 & 12 \\
\hline TAP017 & 25.05 & 121.45 & $\mathrm{E}$ & 46 & 18 \\
\hline TAP019 & 25.04 & 121.49 & $\mathrm{E}$ & 20 & 14 \\
\hline TAP020 & 25.04 & 121.53 & $\mathrm{E}$ & 52 & 21 \\
\hline TAP022 & 25.03 & 121.56 & $\mathrm{D}$ & 82 & 57 \\
\hline TAP023 & 25.00 & 121.45 & $\mathrm{D}$ & 11 & 6 \\
\hline TAP024 & 25.02 & 121.47 & $\mathrm{D}$ & 45 & 17 \\
\hline TAP027 & 25.00 & 121.49 & $\mathrm{D}$ & 16 & 5 \\
\hline TAP028 & 25.00 & 121.50 & $\mathrm{D}$ & 27 & 12 \\
\hline TAP030 & 25.00 & 121.52 & $\mathrm{D}$ & 29 & 21 \\
\hline TAP031 & 25.02 & 121.54 & $\mathrm{D}$ & 22 & 23 \\
\hline TAP032 & 25.00 & 121.47 & $\mathrm{D}$ & 89 & 25 \\
\hline TAP033 & 24.97 & 121.53 & $\mathrm{D}$ & 28 & 20 \\
\hline TAP037 & 25.04 & 121.43 & $\mathrm{D}$ & 24 & 29 \\
\hline TAP038 & 25.02 & 121.41 & $\mathrm{D}$ & 35 & 32 \\
\hline TAP043 & 25.00 & 121.41 & $\mathrm{D}$ & 46 & 26 \\
\hline TAP048 & 24.97 & 121.43 & $\mathrm{D}$ & 16 & 9 \\
\hline TAP053 & 24.95 & 121.51 & $\mathrm{D}$ & 62 & 47 \\
\hline TAP054 & 25.00 & 121.44 & $\mathrm{D}$ & 12 & 14 \\
\hline TAP071 & 25.00 & 121.61 & $\mathrm{D}$ & 26 & 15 \\
\hline TAP093 & 25.01 & 121.56 & $\mathrm{E}$ & 28 & 24 \\
\hline
\end{tabular}


include effects of source rupture peculiarities and inhomogeneous propagation path. On the other hand, when using a large enough number of events varied by magnitude, source depth and azimuth, the effects of focal mechanism and directivity are expected to be averaged out. The approach was applied to evaluate the characteristics of spectral amplification for (1) particular sites in Taipei basin (Sokolov et al. 2000, 2001; Sokolov and Jean 2002; ) and (2) generalised site conditions (classes) in Taiwan (Sokolov et al. 2003, 2004, 2007).

The specification of the "very hard rock" spectrum is of particular significance in the approach. The ground motion database collected in Taiwan provides an opportunity to study both regional source scaling (e.g., Tsai 1997) and attenuation models (e.g., Wang 1988, 1993), as well as local site response upon earthquake ground motion. The models of Fourier amplitude spectrum (FAS) for typical site conditions were analyzed by Sokolov et al. $(2000,2003,2004)$. Recently, Sokolov et al. (2005b, 2006) re-evaluated the FAS models for various source zones in Taiwan using a large number of acceleration records obtained from earthquakes that occurred during 1992 - 2004. The analyzed earthquake source zones are the following. The zone ST contains shallow (hypocentral depth less than $30-35 \mathrm{~km}$ ) earthquakes that occurred within Taiwan Island. The zone SO represents shallow earthquakes that occurred to the east of the island under the ocean. The zone DT contains records from deep (hypocentral depth more than $30-35 \mathrm{~km}$ ) earthquakes. The parameters of the regional FAS model are summarized in Table 2 (see also Sokolov et al. 2006). The value of seismic moment is estimated from regional relationships between seismic moment and local magnitude.

\section{INPUT DATA AND PROCESSING}

The data were recorded by the Taiwan Strong Motion seismic network implemented by the Seismological Observation Center of the Central Weather Bureau (CWB), Taiwan, ROC. More than 650 digital free field strong-motion instruments are installed in this network. Each station is equipped with one strong-motion instrument - a forcebalanced three-component accelerometer. Most instruments (Geotech and Terra Tech instruments) have 16-bit and some instruments (Kinemetrics) have 24-bit resolution. These in-

Table 2. Seismological parameters of the VHR spectral model for the Taiwan earthquakes.

\begin{tabular}{ll}
\hline \multicolumn{1}{c}{ Parameter $^{\mathrm{a}}$} & \multicolumn{1}{c}{ Description } \\
\hline Fourier acceleration spectrum A $(f)$ & $A(f)=(2 \pi f)^{2} C S(f) D(R, f) I(f)$ \\
The scaling factor $C$ & $C \sim 1 /\left(4 \pi \rho \beta^{3} R\right)$ for $\mathrm{R}<40 \mathrm{~km} ;$ \\
& $C \sim 1 /\left(4 \pi \rho \beta^{3} R_{1}\right)\left(\mathrm{R}_{1}=40\right)$ for $\mathrm{R}>40 \mathrm{~km}$ \\
Source spectrum $S(f)$ & Brune $(1970) \omega$-square, point source $S(f)=M_{0} /\left[1+\left(f / f_{0}\right)^{2}\right]$ \\
Corner frequency $f_{0}$ & $f_{0}=4.9 \times 10^{6} \beta\left(\Delta \sigma / M_{0}\right)^{1 / 3}$ \\
Stress parameter $\Delta \sigma($ bar $)$ & Zone ST - increase from 100 bars for M $=5$ to 300 bars for M $=7.0 ;$ \\
& Zone SO - 100 bars; \\
Zone DT - 300 bars. \\
Shear velocity, $\beta\left(\mathrm{km} \mathrm{sec}{ }^{-1}\right)$ & 2.8 \\
Frequency-dependent attenuation $D(R, f)$ & 3.6 \\
Path attenuation $Q(f)$ & $D(R, f)=\exp [-\pi f R / O(f) \beta] P\left(f, f_{\max }\right)$ \\
& Zone ST - $80 f^{0.9} ;$ \\
Zone SO - $120 f^{0.8} ;$ \\
High-frequency filter $P(f)$ & Zone DT - $60 f^{1.0}$ \\
& $P(f)=\exp (-\pi \kappa f)($ Anderson and Hough 1984$)$ \\
& $\kappa=0.01 \mathrm{M}$ \\
\hline
\end{tabular}

* ${ }^{\mathrm{a}} f$ is the frequency, $\mathrm{Hz} ; \mathrm{R}$ is the source-to-site (hypocentral) distance, $\mathrm{km} ; M_{0}$ is the seismic moment. 
struments are capable of recording high-resolution ground motion within $\pm 2 \mathrm{~g}$ and with a pre-event and a post-event memory. All stations have AC power and when the power system is shut down by an earthquake or other problem, the recording system can still operate by the internal DC power for about 4 days.

Fourier amplitude spectra were calculated, using 10\% cosine window tapered on both sides, for selected parts (the strongest shaking) of the acceleration records (Fig. 2). The strongest part of the shaking contains the S-wave portion and, in some cases, surface waves from large distant earthquakes and additional waves generated within the basin. For selection of the part of the record to be processed we used a window containing $90 \%$ of total energy using the integral $I(t)=\int_{t=t_{s}}^{t} a^{2}(t) d t$, where $t_{s}$ is the time of S wave arrival. In some case, where the length of the record is not long enough, expert decision was applied. The calculated Fourier spectra were smoothed twice within $0.2 \mathrm{~Hz}$ running window.

For the low-frequency range, besides the noise level, it is necessary to consider the effect of truncation in the time domain (Bath 1974). The truncation leads incorrectly to a flat spectrum for long periods. It is recommended to use a time-domain-window length at least equal to twice the lowest analyzed wave period. Thus, the combined effect of noise and truncation lead to different lower frequency values for various records. As a result, the number of analyzed spectral amplitudes in the low-frequency range was smaller than that at the higher frequencies. The truncation effect is significant especially for spectral analysis of records from small earthquakes, for which the signal duration does not exceed 2 - 3 seconds. For the whole data set, the lowest frequencies varied from 0.25 to $1.0 \mathrm{~Hz}$ depending on the station and magnitude range.

\section{$20020331 \mathrm{M}=6.8$ H 14 km R 91 km}
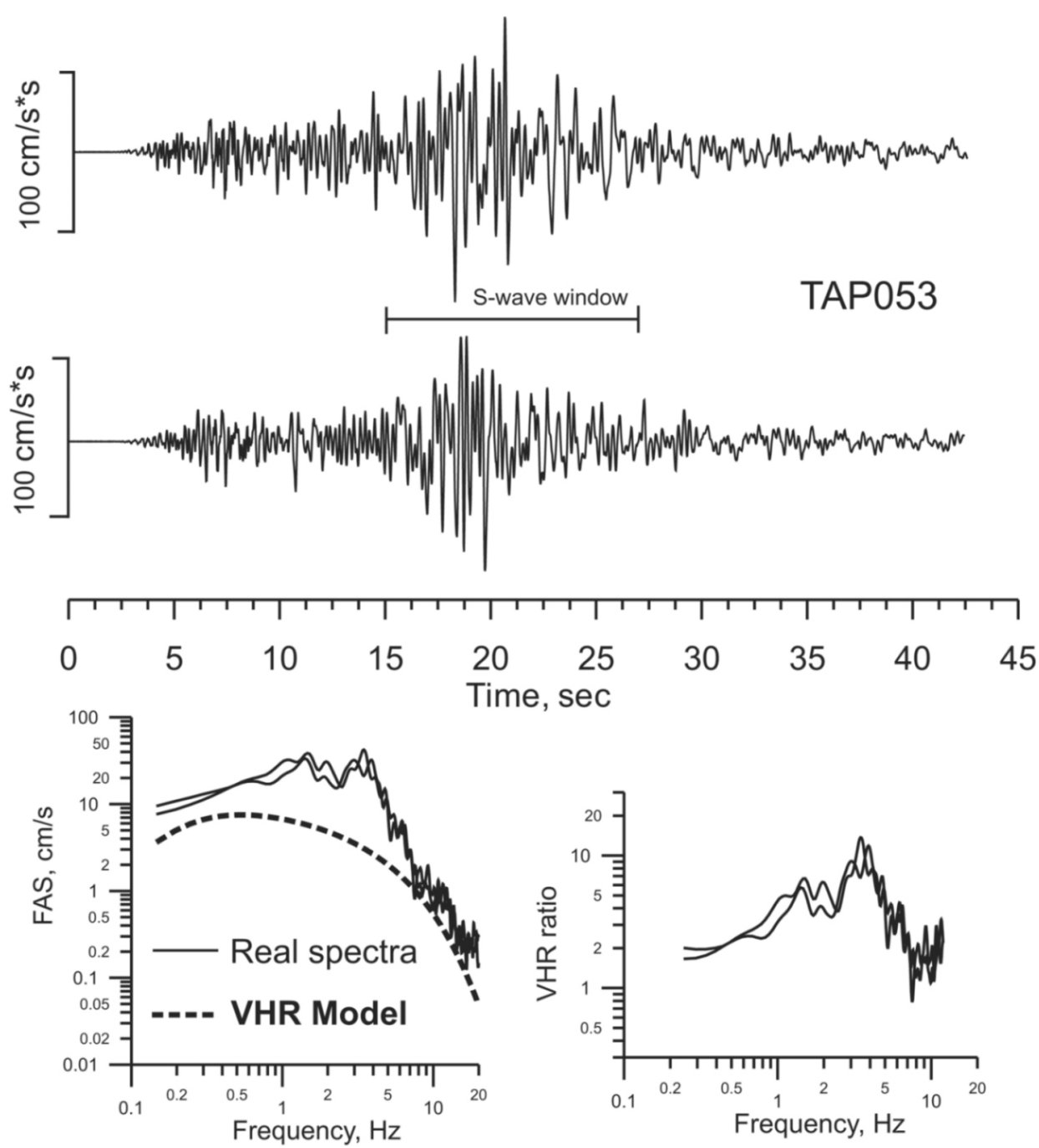

Time, sec

Fig. 2. Calculation of the VHR spectral ratio (magnitude $M$, focal depth $H$, hypocentral distance $R$ ). 
Reference VHR spectra were calculated using the models described above (Table 2). Estimations of seismic moment $\left(M_{0}\right)$ and stress parameter $(\Delta \sigma)$ are not available for almost all of the selected earthquakes. When using the empirical relationship between seismic moment and local magnitude, it is necessary to bear in mind the possible scatter of the $M_{0}$ values. Ideally, the observed and theoretical spectra should fit each other at low frequencies where the influence of local geology is believed to be negligible. The influence may be very small for the case of rock sites or sites with a thin layer of sediments over rigid bedrock. Such a case may be considered as a reference site when the proper values of earthquake source parameters are selected to be used in the FAS model. It has been found in our previous study (Sokolov et al. 2000) that station TAP053 satisfies the criteria to be considered as a reference site. The site response at the station is characterized by narrow-band amplification at frequencies around $4 \mathrm{~Hz}$. Figure 3 shows examples of the observed and modelled spectra for station TAP053. Similarly, station TAP071 with small-amplitude site amplification is located outside the basin that minimizes possible influence of relatively long-period waves trapped within the basin.

\section{RESULTS AND DISCUSSION}

Ideally, for the case of linear soil response upon earthquake motion, site amplification functions or the ratios between the observed and the modelled spectra should not depend on earthquake magnitude. On the other hand, site effect should be independent on the applied source models. Therefore, if the proper spectral models are used for various magnitudes, the characteristics (averaged amplitudes and shape) of the ratios between the observed and the modelled spectra should be approximately the same for different earthquakes, at least for those of similar distance and azimuth. The characteristics of the VHR ratio evaluated for stations TAP073 and TAP071 are shown in Fig. 4. In general, the ratios obtained using records from the deep (DVHR) and shallow (SVHR) earthquakes exhibit a similar nature. The SVHR ratios are characterized by slightly higher amplitudes at frequencies less than 2 - $3 \mathrm{~Hz}$ than the DVHR ratios, which may be explained by the presence of surface waves generated by shallow and distant earthquakes.

Let us analyse the VHR ratios calculated for stations located within the basin. The stations near the basin edge (Fig. 4) with relatively shallow deposits (e.g., TAP002,
$19991101 \mathrm{M}=6.9 \mathrm{H} 31 \mathrm{~km} \mathrm{R} 100 \mathrm{~km}$
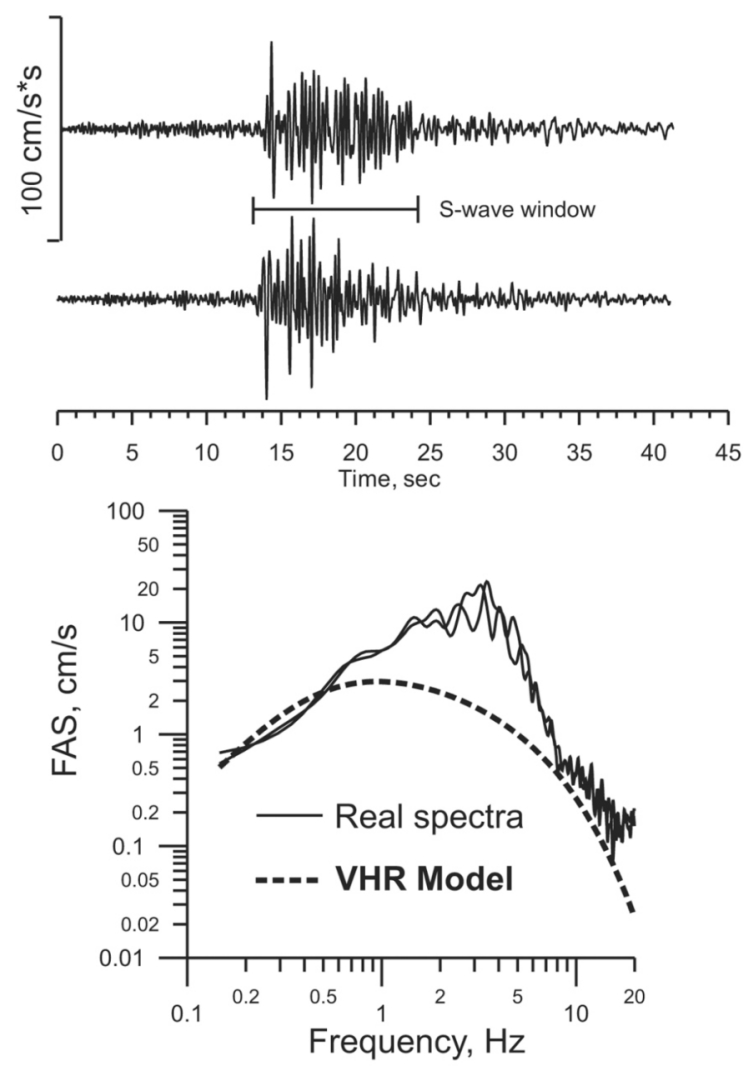

$19951201 \mathrm{M}=5.7 \mathrm{H} 45 \mathrm{~km}$ R $51 \mathrm{~km}$
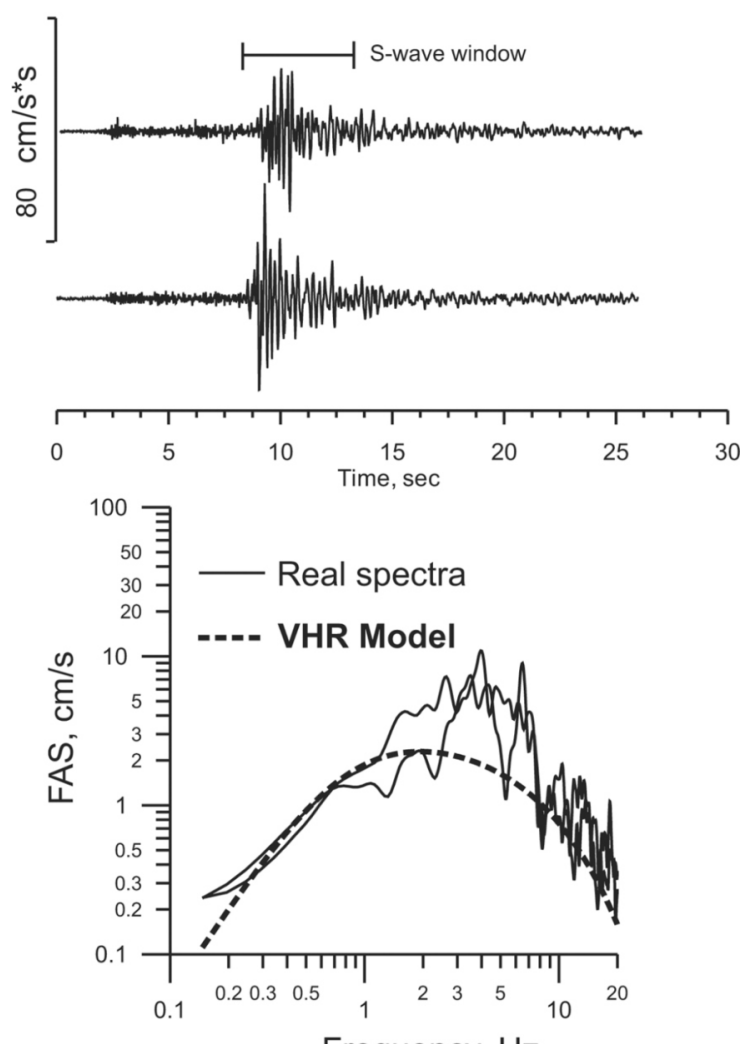

Frequency, $\mathrm{Hz}$

Fig. 3. Station TAP053, comparison of the spectra of real records from particular earthquakes (magnitude M, depth H, hypocentral distance R) and the modelled spectra (VHR model). 

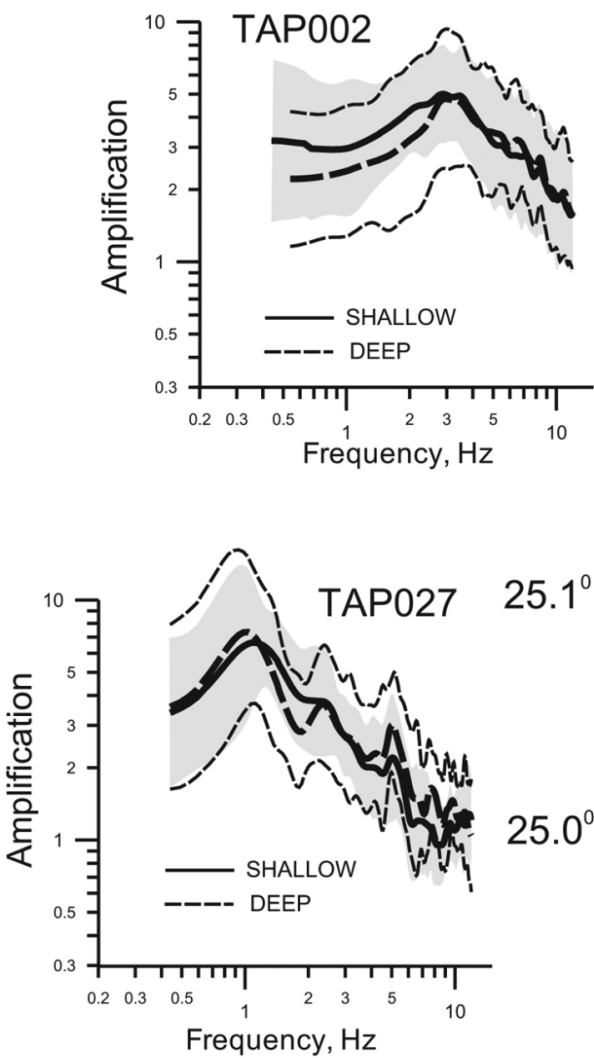
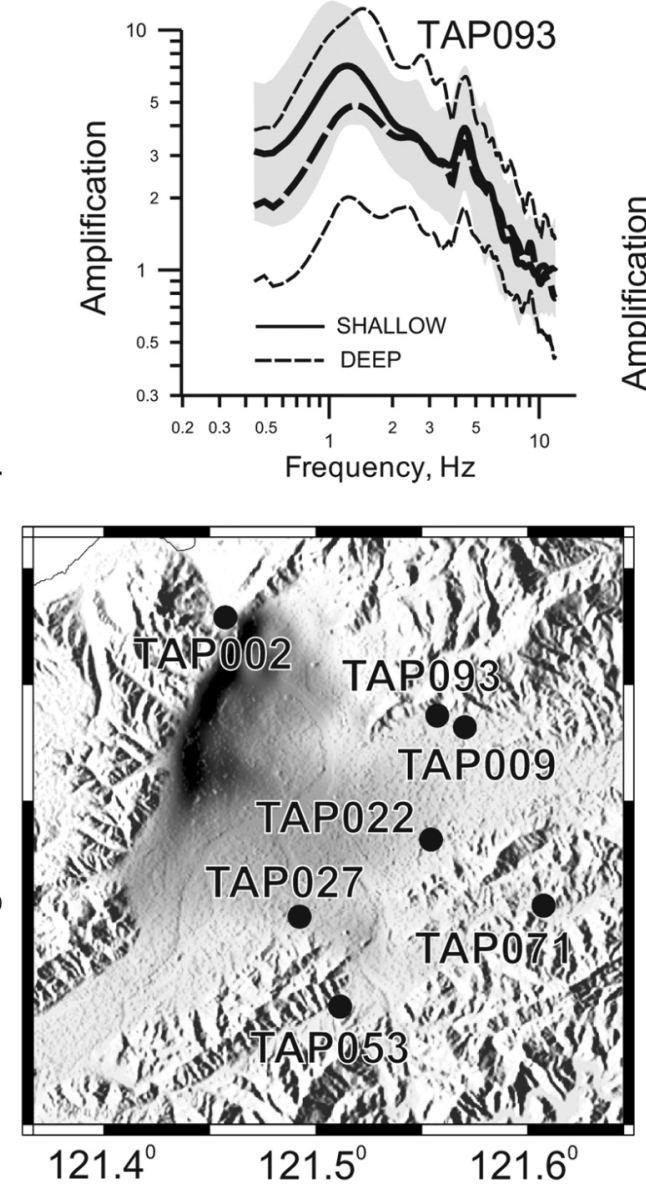
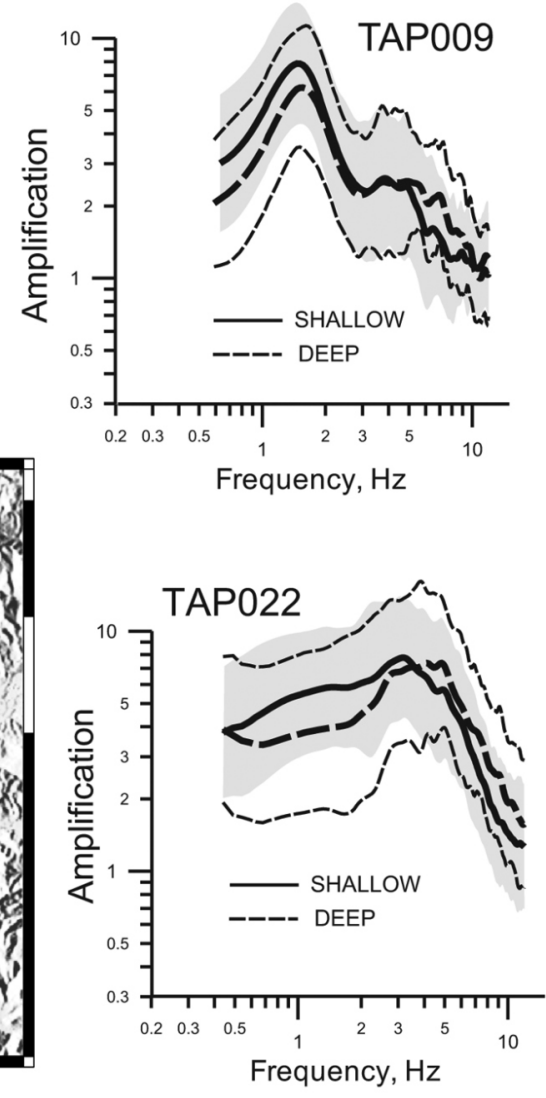
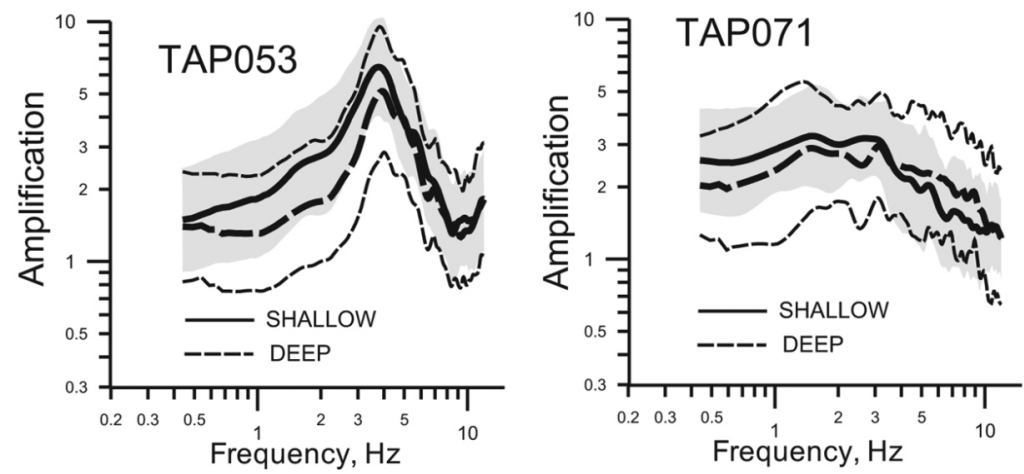

Fig. 4. Characteristics of the VHR spectral ratios (mean amplitude values and 1 standard deviation limits) evaluated for stations located outside the Taipei basin and near the basin edge. The depth of Quaternary sediments is shown in gradations of grey colour.

TAP009, TAP022, TAP027, and TAP093) reveal the same character in terms of the ratios, as the stations located outside the basin, namely: the SVHR and the DVHR ratios show approximately the same amplitudes in the whole considered frequency range. For the central part of the basin (Fig. 5), the difference between the SVHR and DVHR ratios at low frequencies becomes much larger than that for the basin edge. Figure 6 shows the frequency-dependent averaged ratio between the SVHR and DVHR amplitudes calculated for the considered sets of stations located (a) near the basin edge and outside the basin and (b) in the central part of the basin.

We assume that the difference between the SVHR and DVHR ratios at low frequencies most likely reflects the influence of additional waves generated within the basin. However, to check the suggestion we have to answer the following question: in what extent could the VHR curves reflect real site response? We used a simple 1-D technique to calculate theoretical spectral amplification of a multilayered soil column overlying a rigid half-space for SH- 
and SV-waves approaching the bottom of the soil with arbitrary angles of incidence.

The subsurface geology of the Taipei basin has been established by boring, and electrical and seismic prospecting (Lee et al. 1978; Fei and Lai 1994; Wang et al. 1994, 1996, 2004; Wang and Lee 2002). The geological structure inside the basin consists of Quaternary layers above tertiary base rock. The stratigraphic formations of the Quaternary layers are, in descending order, surface soil, the Sungshan For- mation, the Chingmei Formation, and the Hsinchuang Formation. The Sungshan Formation is composed mainly of alternating beds of silty clay and silty sand, and covers almost the whole Taipei basin. The Chingmei Formation is a fanshaped body of conglomerate deposits. The Hsinchuang Formation, recently renamed into the Wuku and Panchiao Formations, consists of bluish gray and clayey sand with some conglomerate beds. The available data, which include the digital models of thickness of the whole Quartenary de-
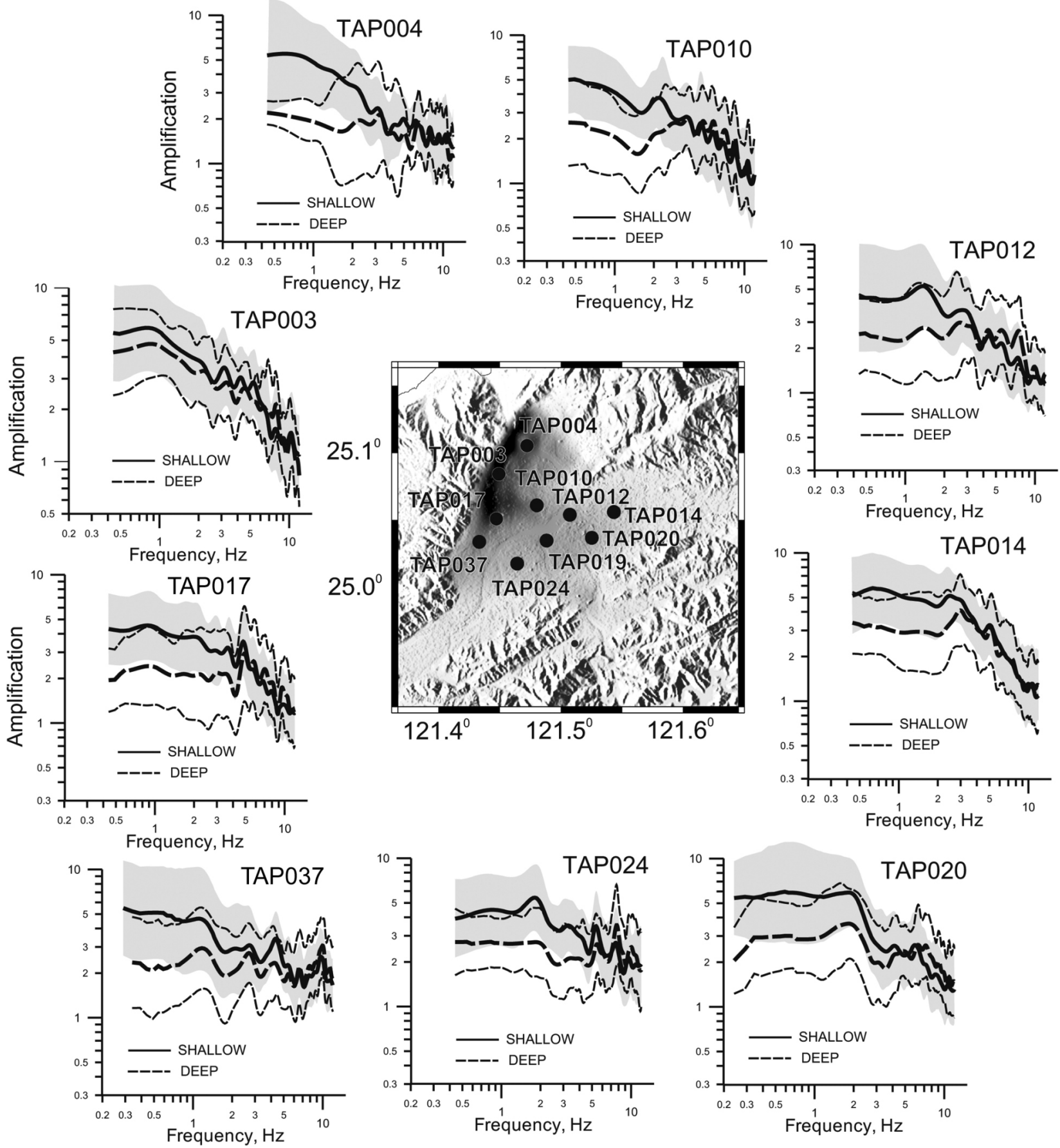

Fig. 5 Characteristics of the VHR spectral ratios (mean amplitude values and 1 standard deviation limits) evaluated for stations located within the Taipei basin and near the basin edge. The depth of Quaternary sediments is shown in gradations of grey. 


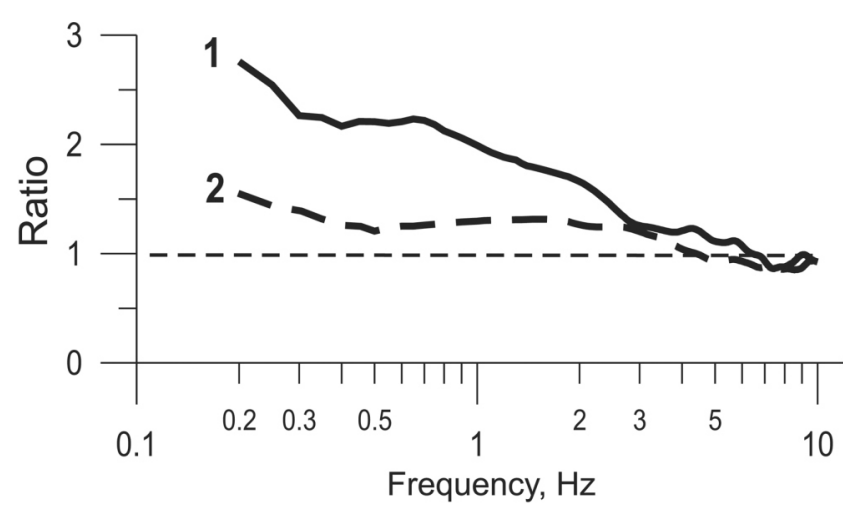

Fig. 6. Ratios between the VHR data for shallow and deep earthquakes (SVHR/DVHR) averaged for the considered stations located near the basin edge (curve 2) and within the basin (curve 1).

posits and of the Sungshan Formation, allow constructing numerical models of soil column for several sites and calculating theoretical amplification (Wen and Peng 1998a, b; Sokolov et al. 2000; Fletcher and Wen 2005).

The quality factor $Q(f)$ that represents the damping in the soil was evaluated by Wen and Peng (1998b). Depending on the depth interval, the Q-model may be described as follows: 0 - $30 \mathrm{~m}, Q(f)=3.6 f^{0.96} ; 30$ - $60 \mathrm{~m}, Q(f)=7.2 f^{0.99}$; 60 - $90 \mathrm{~m}, Q(f)=10 f^{1.17} ; 90-140 \mathrm{~m}, Q(f)=40 f^{1.24}$. When constructing the numerical models of soil columns, we assigned every Q-model to particular stratigraphic formation as follows: the Sungshan Formation, upper part $-Q(f)=3.6 f^{0.96}$, lower part - $Q(f)=10 f^{1.17}$; the Chingmei Formation - $Q(f)=$ $40 f^{1.24}$. A low-damping Q-model $\left[Q(f)=200 f^{1.0}\right]$ was assigned to the the Wuku and Panchiao Formations.

We have to note that the geotechnical properties of the Quaternary deposits in the Taipei basin have still not been studied in detail. A relatively low $Q$ value, as compared with the averaged data, is expected for high crack density and fluid-saturated soil in the Taiwan region (Shieh 1992). Amplitudes of ground motion amplification are very sensitive to the degree of damping (quality factor). Therefore, for comparison we used two variants of the Q-model. In the first one (Q1-model), the quality factors were taken as those provided by Wen and Peng (1998b). The higher, gradually increasing with depth, values of the quality factor were accepted in the second model (Q2-model). Table 3 lists parameters of the soil models for particular sites.

We calculated the theoretical spectral amplification for S-wave assuming the bottom of the basin as a rigid halfspace. The tertiary basement could not be considered as "very hard rock" as used in our spectral model. Therefore, when comparing the VHR ratios and results of the theoretical modeling, the generalized hard-rock amplification (see Sokolov et al. 2007) was added to the 1D modeling.

Of course, the theoretical models of layered deposits in many cases can provide only a rough approximation to reality. For example, the soil layers can be characterized, as a rule, by a gradual change of shear-wave velocity with depth. This phenomenon causes a broadband amplification. The theoretical model describes the layers by uniform velocities, which results in separate resonance peaks. We do not know exactly the geotechnical properties and thickness of the considered stratigraphic formations in every considered point. This may cause discrepancies in the amplitude and the location of particular amplification peaks between the empirical and the modeled spectral ratios.

Despite the approximate character of the 1D model, the results of the modeling show that in almost all considered cases ( 30 points or Taipei network stations, except stations TAP003 and TAP016) the theoretical spectral ratios show a good agreement with the VHR data obtained from records of deep earthquakes (Fig. 7). In general, the site amplification characteristics for the areas located near the basin edge (e.g., TAP002, TAP009, TAP022, TAP027, TAP028, TAP030, TAP033, TAP043, TAP048, TAP053, and TAP093) reveal one or two separate peaks within relatively narrow frequency bands, reflecting influence of particular layers. The areas with thick sediments are characterized by broadband amplification. The comparison of empirical and theoretical data may also allow a proper selection of geotechnical properties for further, more detailed, modeling.

To analyse site amplification characteristics obtained from records of shallow earthquakes we applied the following scheme. The FAS amplitudes for the records obtained outside the basin from deep $\left[A_{\text {OUTD }}(f)\right]$ or shallow $\left[A_{\text {OUTS }}(f)\right]$ earthquakes may be expressed as follows:

$A_{\text {OUTD }}(f)=A_{\text {VHR }}(f) \times A M P L_{D}(f)$, or

$A_{\text {OUTS }}(f)=A_{V H R}(f) \times A M P L_{S}(f)$

$A M P L_{D}(f)=S G(f), A M P L_{S}(f)=S P(f) \times S G(f)$

where $f$ is the frequency, $\mathrm{Hz} ; A_{V H R}(f)$ is the spectrum at rock basement; $A M P L(f)$ is the overall spectral amplification; $S P(f)$ reflects influence of propagation path (surface waves); and $S G(f)$ is the amplification caused by site geology. The FAS amplitudes for the records from shallow earthquakes obtained inside the basin $A_{I N B S}(f)$ (besides the influence of propagation path and local geology) may reflect influence of the additional waves generated within the basin (basin factor) $S B(f)$ and the expression may be written as:

$A_{I N B S}(f)=A_{V H R}(f) \times S P(f) \times S G(f) \times S B(f)$

Let us, for example, consider a pair of stations that are located outside (e.g., TAP053) and within (e.g., TAP020) the basin (see Figs. 4, 5), which recorded a large numbers of earthquakes (Table 1). The VHR ratio averaged from the available set of deep earthquakes $\left(\mathrm{VHR}_{\mathrm{D}}\right)$ can be interpreted as the influence of local geology, or the $S G(f)$ term, for both stations, i.e., $V_{H R}(f)=A M P L_{D}(f)=S G(f)$. The ratio 
$S D R(f)$ between the averaged VHR ratio for shallow earthquakes $\left(\mathrm{VHR}_{\mathrm{S}}\right)$ and the averaged VHR ratio for deep earthquakes $\left(\mathrm{VHR}_{\mathrm{D}}\right)$ for station TAP053 (reference station located outside the basin) may be considered as describing the influence of propagation path, or the $S P(f)$ term, i.e.,:

$\operatorname{SDR}_{T A P 053}(f)=\frac{V H R_{S}(f)}{V H R_{D}(f)}=\frac{A M P L_{S}(f)}{A M P L_{D}(f)}=S P(f)$

The ratio for stations that are located inside the basin, e.g., TAP020, may be considered as a description of the joint influence of propagation path and the basin, or $\operatorname{SDR}_{\text {TAP020 }}(f)$
$=S P(f) \times S B_{T A P 020}(f)$. Of course, in this case the function $S D R_{\text {TAP020 }}(f)$ reflects only the generalized characteristics obtained from many earthquakes occurring at different locations. However, when comparing the data at both stations from the same set of shallow earthquakes, we can assume that generalized characteristics of the additional waves generated within the basin, or the $S_{\text {TAP020 }}(f)$ term, may be evaluated as:

$S B_{T A P 020}(f)=S D R_{\text {TAP } 020}(f) / S D R_{\text {TAP 053 }}(f)$

However, station TAP053 is characterized by a highamplitude amplification at frequencies between $2-5 \mathrm{~Hz}$

Table 3. Parameters of the models of soil columns for particular stations.

\begin{tabular}{|c|c|c|c|c|}
\hline Geological Formation & $\mathrm{V}_{\mathrm{S}}\left(\mathrm{km} \mathrm{s}^{-1}\right)$ & Density $\left(\mathrm{g} \mathrm{cm}^{-3}\right)$ & Thickness (km) & Q-model $\left(Q_{0} f^{n}\right)(\mathrm{Q} 1 ; \mathrm{Q} 2)$ \\
\hline \multicolumn{5}{|c|}{ TAP001 } \\
\hline \multirow[t]{3}{*}{ Sung-Shan } & 0.16 & 1.80 & 0.030 & $3.6 f^{0.96} ; 10 f^{1.0}$ \\
\hline & 0.24 & 1.80 & 0.005 & $7.2 f^{0.99} ; 20 f^{1.0}$ \\
\hline & 0.34 & 1.85 & 0.005 & $10.2 f^{1.17} ; 30 f^{1.0}$ \\
\hline Chingmei & 0.50 & 1.90 & 0.060 & $40.7 f^{1.24} ; 60 f^{1.0}$ \\
\hline Wuku & 0.60 & 2.00 & 0.040 & $200 f^{1.0}$ \\
\hline Base rock & 1.00 & 2.10 & - & - \\
\hline \multicolumn{5}{|c|}{ TAP004 } \\
\hline \multirow[t]{3}{*}{ Sung-Shan } & 0.16 & 1.80 & 0.010 & $3.6 f^{0.96} ; 10 f^{1.0}$ \\
\hline & 0.24 & 1.80 & 0.040 & $7.2 f^{0.99} ; 20 f^{1.0}$ \\
\hline & 0.34 & 1.85 & 0.020 & $10.2 f^{1.17} ; 30 f^{1.0}$ \\
\hline Chingmei & 0.50 & 1.90 & 0.060 & $40.7 f^{1.24} ; 60 f^{1.0}$ \\
\hline Wuku & 0.60 & 2.00 & 0.100 & $200 f^{1.0}$ \\
\hline Panchiao & 0.80 & 2.10 & 0.140 & $200 f^{1.0}$ \\
\hline Base rock & 1.20 & 2.10 & - & - \\
\hline \multicolumn{5}{|c|}{ TAP093 } \\
\hline \multirow[t]{2}{*}{ Sung-Shan } & 0.16 & 1.80 & 0.020 & $3.6 f^{0.96} ; 10 f^{1.0}$ \\
\hline & 0.24 & 1.80 & 0.010 & $3.6 f^{0.96} ; 10 f^{1.0}$ \\
\hline Chingmei & 0.50 & 1.60 & 0.005 & $40.7 f^{1.24} ; 60 f^{1.0}$ \\
\hline Base rock & 1.20 & 2.10 & - & - \\
\hline \multicolumn{5}{|c|}{ TAP023 } \\
\hline \multirow[t]{3}{*}{ Sung-Shan } & 0.17 & 1.80 & 0.010 & $3.6 f^{0.96} ; 10 f^{1.0}$ \\
\hline & 0.24 & 1.80 & 0.010 & $7.2 f^{0.99} ; 20 f^{1.0}$ \\
\hline & 0.34 & 1.85 & 0.020 & $10.2 f^{1.17} ; 30 f^{1.0}$ \\
\hline Chingmei & 0.50 & 1.90 & 0.040 & $40.7 f^{1.24} ; 60 f^{1.0}$ \\
\hline Wuku & 0.60 & 2.00 & 0.060 & $200 f^{1.0}$ \\
\hline Panchiao & 0.80 & 2.10 & 0.020 & $200 f^{1.0}$ \\
\hline Base rock & 1.20 & 2.10 & - & - \\
\hline
\end{tabular}



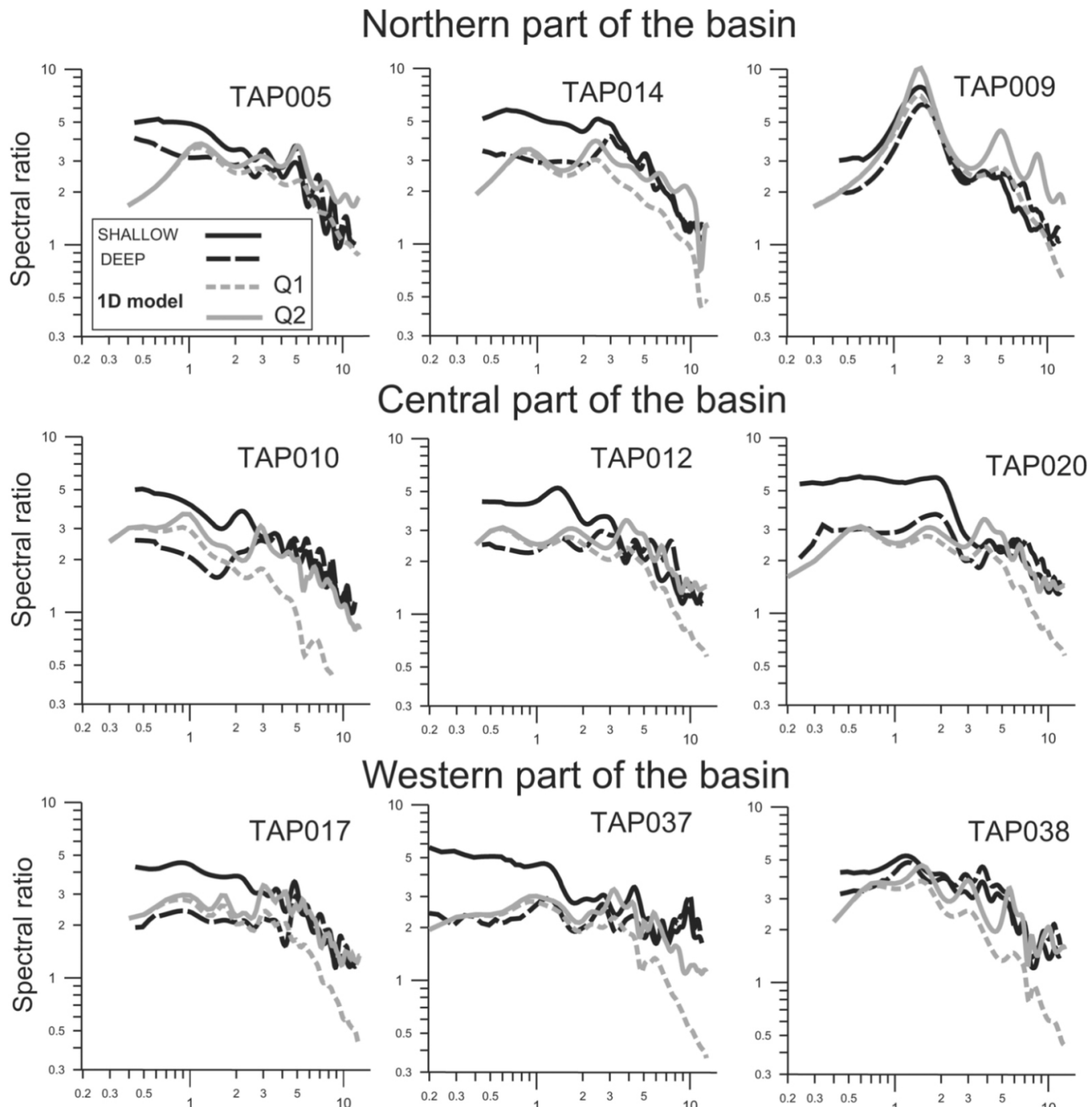

Western part of the basin
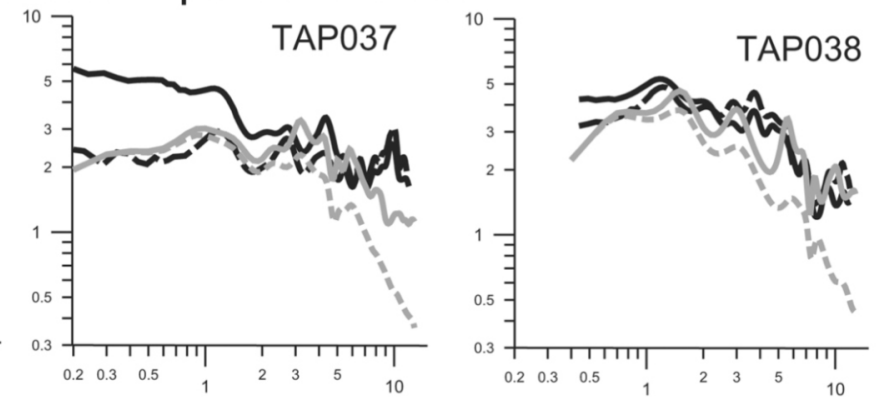

Southern and Eastern parts of the basin
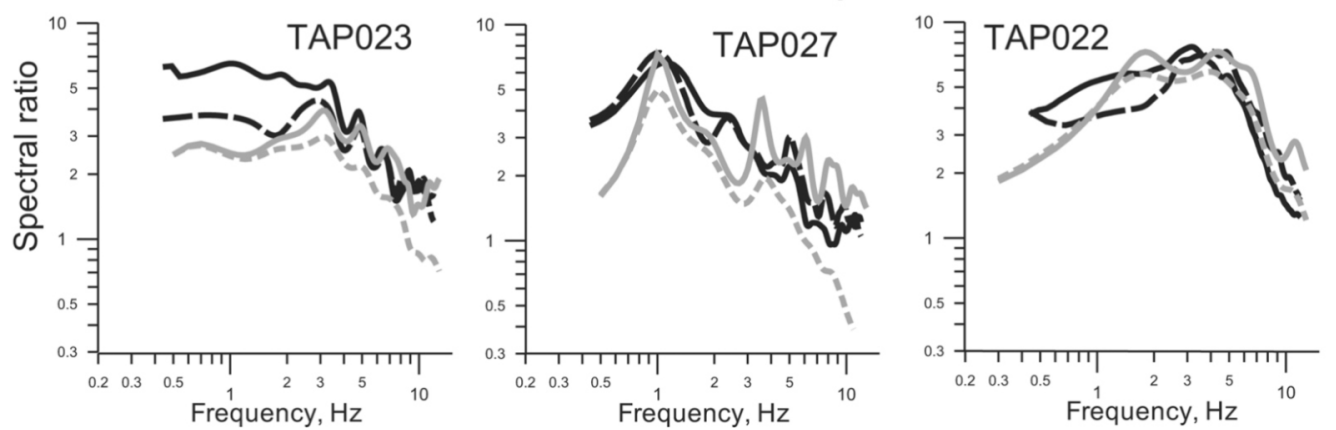

Fig. 7. Comparison of the VHR spectral ratios (average values) calculated using the data from deep and shallow earthquakes and the results of 1D modeling (the Q1- and Q2-models).

(Fig. 4). The high variability of the VHR ratios within this frequency range could cause unstable values of the SDRfactor evaluated form different sets of earthquakes. Therefore, for analysis of the influence of propagation path (SPterm) and the basin effect (SB-term), we also used the data from station TAP071 with a low-amplitude broadband am- plification (Fig. 4).

Figure 8a shows an example of the generalized characteristics of the $S P(f)$ term (influence of propagation path) for stations TAP053 and TAP071 averaging different sets of the data including: (a) all shallow earthquakes; (b) the large magnitude $(M>6.0)$ earthquakes (see also Fig. 1). The in- 
fluence of propagation path, in essence, is a frequency-dependent parameter and it also depends on magnitude of earthquakes. The combined effect of the propagation path $[S P(f)$ term] and the basin $[S B(f)$ term] is shown at Fig. $8 \mathrm{~b}$ for two stations located inside the basin, namely: TAP017 and TAP020. Figure $8 \mathrm{c}$ shows characteristics of the basin effect, or the $S B(f)$ term. Again, the basin effect is a frequencydependent parameter that depends clearly on station location inside the basin. Station TAP017, which is located in the

(a)
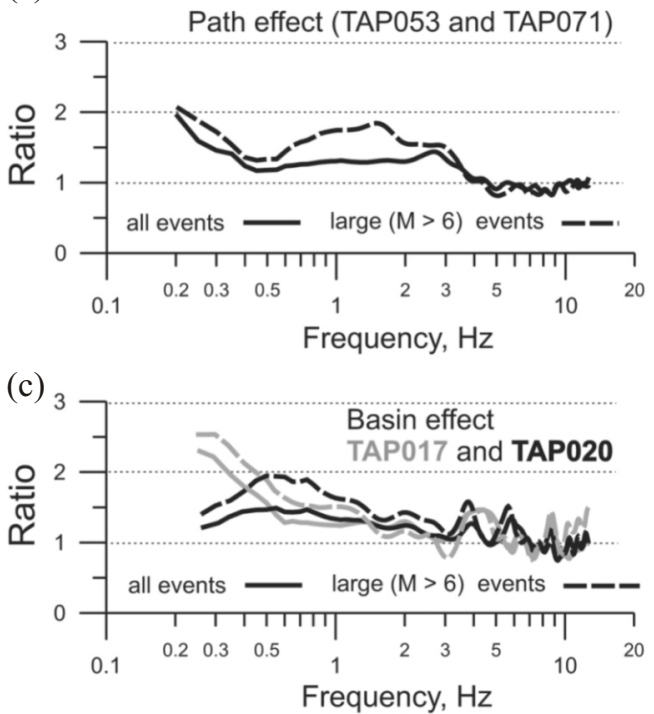

western part of the basin where the sediments thickness is the greatest (Fig. 5), reveals a much higher basin-factor amplification at low frequencies (less than $0.4-0.3 \mathrm{~Hz}$ ) than the station TAP020, which is located in the eastern part of the basin where thin sediments exist.

The average-amplitude frequency-dependent basin effect $[\mathrm{SB}(f)$ term], which is evaluated for a few particular stations within the basin, is shown in Fig. 9. It seems that it is possible to divide the basin into at least three zones showing:

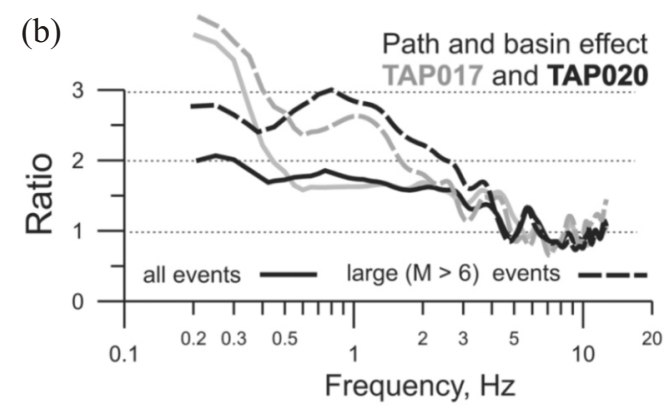

Fig. 8. Frequency-dependent characteristics of site amplification (path and basin effects, see text) averaged for various stations and earthquakes.
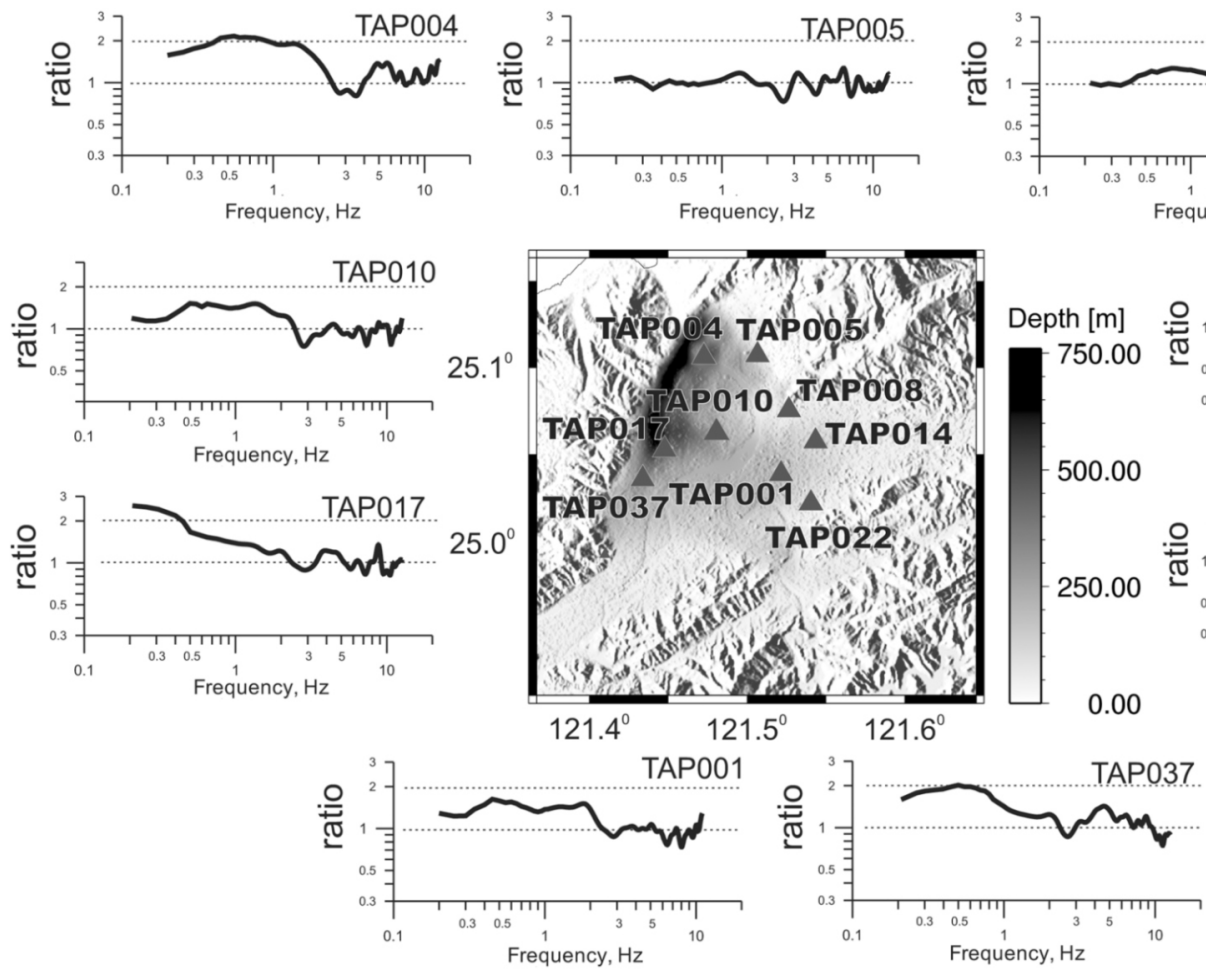

Fig. 9. Characteristics of the basin effect for particular stations averaged using the data from all earthquakes recorded at every station.
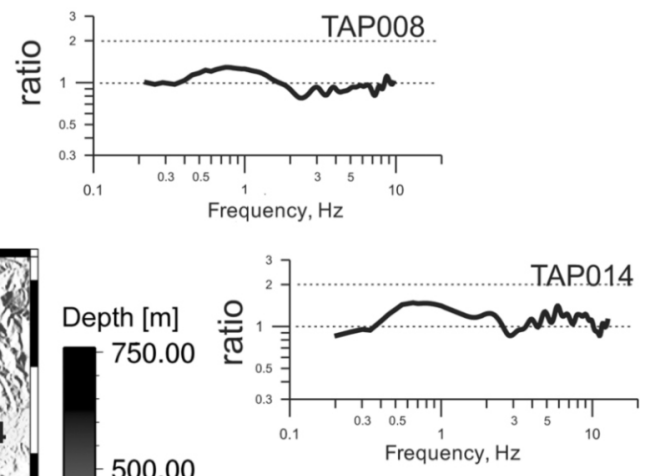

$-500.00$

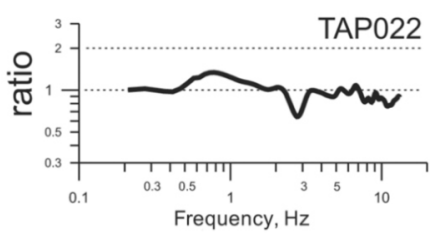

TAP022 
(a) almost negligible amplification due to the basin effect (near the basin edge); (b) a relatively high-amplitude lowfrequency amplification (deepest part of the basin); and (c) a transition zone.

The characteristics of the site response may be evaluated for various sets of shallow earthquakes (e.g., large and small, nearby and distant, etc.). They may be used jointly with regional source scaling and attenuation models, characteristics of propagation path effect and site amplification due to local geology (1D effect) for probabilistic seismic microzonation of the basin when many possible earthquakes lo- cated at different distances and azimuths are considered. Particular events, however, may reveal some peculiarities in frequency content of ground motions (Figs. 10, 11). For example, the data from the shallow event of 31 March 2002 (M 6.8, depth $14 \mathrm{~km}$, also known as the Hualien 331 earthquake) show relatively high amplitudes of amplification as compared with the average values at low frequency range. The data from another large, distant, and shallow event, 1 November 1999 (M 6.9, depth 30 km) are characterized by relatively low amplitudes of amplification as compared with the average values at low frequencies. Even deep earth-

March 31, 2002, M 6.8, $\mathrm{H}=13.8$
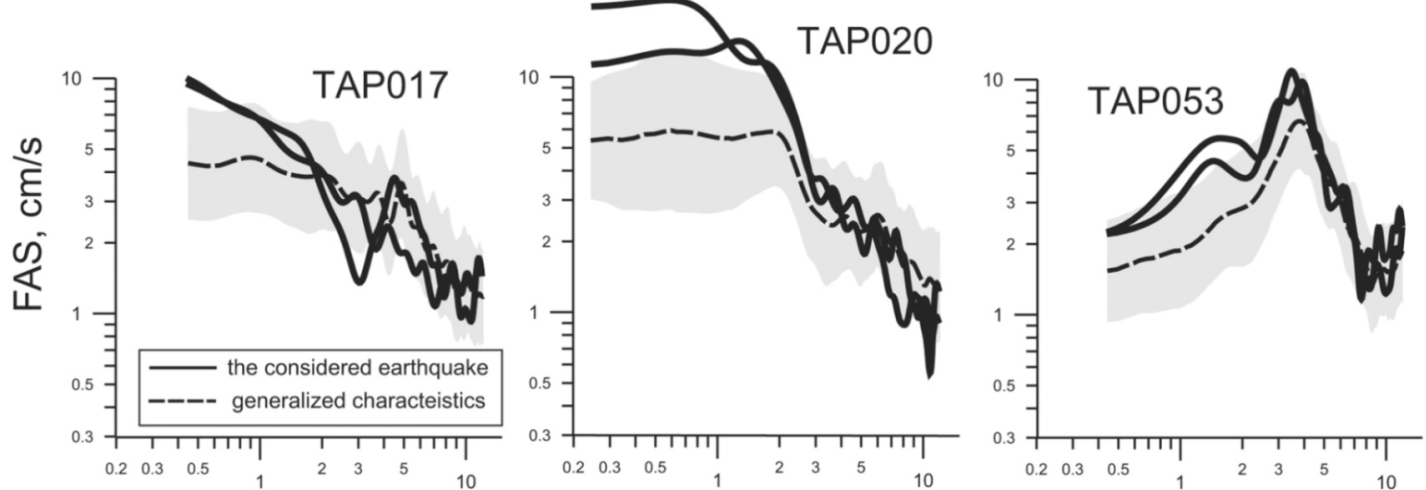

November 11, 1999, M 6.9, $\mathrm{H}=31$
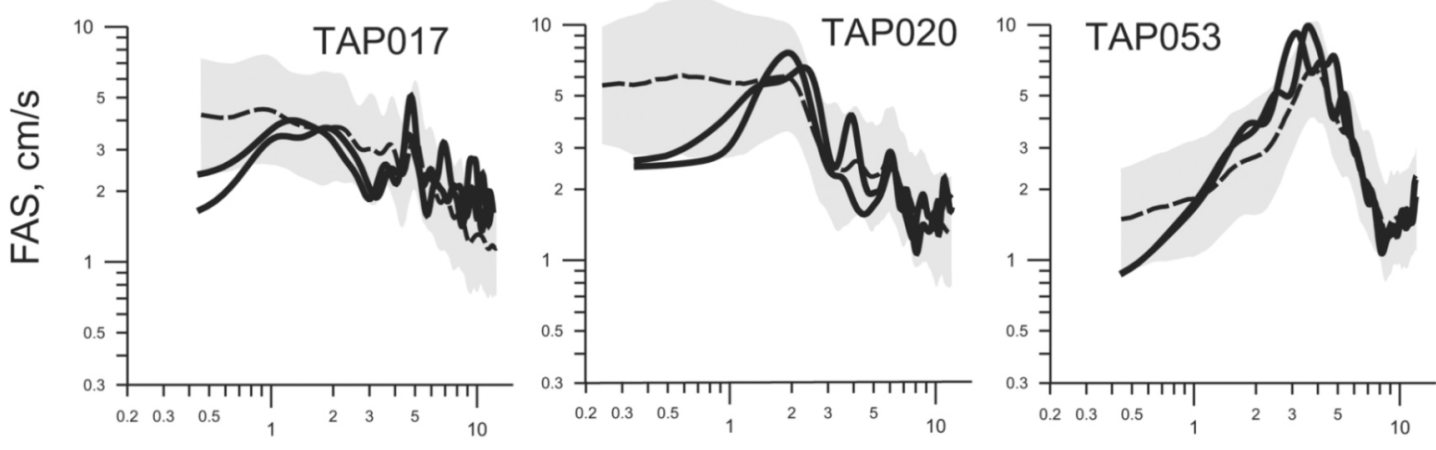

March 24, 1995, M 5.6, H=76
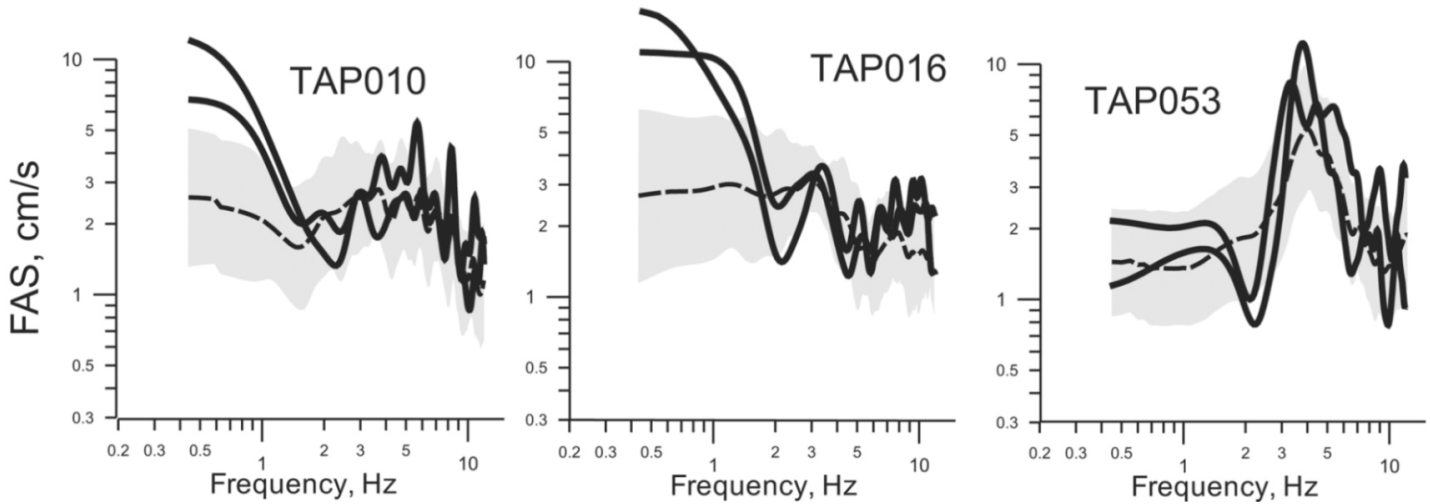

Fig. 10. Comparison of VHR ratios calculated for particular earthquakes of various magnitudes M and depths H (km) (red lines) with the generalized characteristic of the ratios (mean amplitude values and 1 standard deviation limits). 


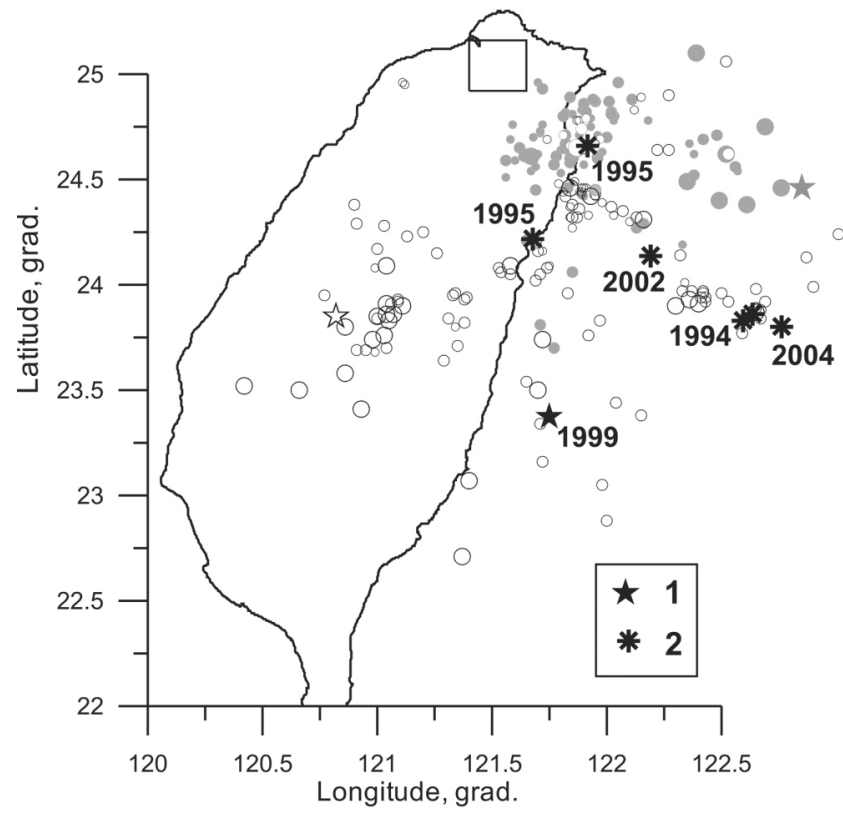

Fig. 11. Location of large earthquakes (see legend in Fig. 1) that revealed peculiarities of the Taipei basin response in low-frequency range. 1 - the earthquake did not reveal unusual low-frequency amplification; 2 - events caused high-amplitude amplification at low frequencies.

quakes, for example the event of 24 March 1995 (M 5.6, depth $76 \mathrm{~km}$ ), may show significant low-frequency basin effect. It has been shown recently (Lee et al. 2009), that deep earthquakes located southeast of the Taipei basin, such as the event of 24 March 1995, may produce high-amplitude low-frequency amplification in the northwestern part of the basin.

Besides the location of the events mentioned above, Fig. 11 shows the locations of a few large shallow earthquakes (symbols N 2) that occurred southeast of the basin that caused high-amplitude low-frequency amplification within Taipei basin. It seems that $2 \mathrm{D}$ and $3 \mathrm{D}$ simulation is necessary to model seismic shaking in the Taipei basin when particularly large events are considered (e.g., so-called "worst-case" or "dominant" earthquakes).

\section{CONCLUSION}

We studied site amplification of the Taipei basin using the available ground-motion database and recently developed regional spectral models (Sokolov et al. 2006). The following conclusions may be drawn from the analysis.

(1) The characteristics of frequency-dependent site response for particular locations or sites (stations of the TSMIP network) in the Taipei basin, which were obtained using records of deep earthquakes (depth $>35 \mathrm{~km}$ ), show good agreement with the theoretical ratios calculated using the
1D-models based on the available geological and geotechnical data.

(2) The data from shallow earthquakes show influence of: (a) surface waves generated by distant sources to the basin; and (b) relatively low-frequency $(<1-2 \mathrm{~Hz})$ waves generated within the basin.

(3) Some shallow earthquakes produce extremely high amplification at frequencies $0.3-1 \mathrm{~Hz}$ within the basin that may be dangerous for high-rise buildings and highway bridges.

The results may be used in probabilistic seismic microzonation of the Taipei basin many earthquakes located at various distances are considered (Sokolov and Chernov 2001; Sokolov et al. 2001). We have to note that frequencydependent amplification functions were obtained in this study within a limited frequency range from 0.3 to $12 \mathrm{~Hz}$. The lower-frequency ground-motion characteristics may be studied using numerical 2D and 3D modeling. For the prediction of seismic influence from particularly large earthquakes, a special procedure combining long-period waveform modeling and stochastic simulation of high-frequency waveforms should be used.

Acknowledgements The authors would like to thank Jer-Ming Chiu for his thoughtful comments and suggestions. The comments from an anonymous reviewer are also gratefully acknowledged. This work was sponsored by National Science Council, ROC (grant NSC 96-2119-M008-007) and Deutsche Forschungsgemeinschaft (DFG), Germany, (project WE 1394/13-1).

\section{REFERENCES}

Anderson, J. and S. Hough, 1984: A model for the shape of the Fourier amplitude spectrum of acceleration at high frequencies. Bull. Seismol. Soc. Am., 74, 1969-1993.

Bard, P. Y., 1995: Effects of surface geology on ground motion: Recent results and remaining issues. Proc. of 10th European Conference on Earthquake Engineering, Balkema, Rotterdam, 305-323.

Bath, M., 1974: Spectral Analysis in Geophysics, Elsevier Scientific Publishing Company, Amsterdam, 563 pp.

Beresnev, I. A., A. M. Nightengale, and W. J. Silva, 2002: Properties of vertical ground motions. Bull. Seismol. Soc. Am., 92, 3152-3164, doi: 10.1785/0120020009. [Link]

Bonilla, L. F., J. H. Steidl, G. T. Lindley, A. G. Tumarkin, and R. J. Archuleta, 1997: Site amplification in the San Fernando valley, California: Variability of site-effect estimation using the S-wave, coda and H/V methods. Bull. Seismol. Soc. Am., 87, 710-730.

Borcherdt, R., 1970: Effect of local geology on ground motion near San Francisco Bay. Bull. Seismol. Soc. Am., 60, 2961.

Castro, R. R., M. Mucciarelli, F. Pacor, and C. Petrungaro, 
1997: S-wave site-response estimates using horizontal-tovertical spectral ratios. Bull. Seismol. Soc. Am., 87, 256260.

Chen, K. C., 2003: Strong ground motion and damage in the Taipei basin from the Moho reflected seismic waves during the March 31, 2002, Hualien, Taiwan, earthquake. Geophys. Res. Lett., 30, 1551, doi: 10.1029/2003GL 017193. [Link]

Chen, S. Z. and G. M. Atkinson, 2002: Global comparisons of earthquake source spectra. Bull. Seismol. Soc. Am., 92, 885-895, doi: 10.1785/0120010152. [Link]

Fei, L. Y. and T. C. Lai, 1994: The preliminary result of an integrated survey of subsurface geology and engineering environment of the Taipei basin. Proc. of the Joint Symp. on Taiwan Quarternary (5) and on Investigation of Subsurface Geology/Engineering Environment of Taipei Basin, 121-128.

Field, E. H. and K. H. Jacob, 1995: A comparison and test of various site-response estimation techniques including three that are not reference-site dependent. Bull. Seismol. Soc. Am., 85, 1127-1143.

Fletcher, J. B. and K. L. Wen, 2005: Strong ground motion in the Taipei basin from the 1999 Chi-Chi, Taiwan, earthquake. Bull. Seismol. Soc. Am., 95, 1428-1446, doi: 10.1785/0120040022. [Link]

Huang, H. C., Y. T. Yang, and H. C. Chiu, 2002: Site response evaluation using the $\mathrm{H} / \mathrm{V}$ ratio at the Yan-Liau station in Hualien, Taiwan. Pure Appl. Geophys., 159, 2715-2731, doi: 10.1007/s00024-002-8755-2. [Link]

Kuo, K. W., T. C. Shin, and K. L. Wen, 1995: Taiwan strong motion instrumentation program (TSMIP) and preliminary analysis of site effects in Taipei basin from strong motion data. In: Cheng, F. Y. and M. S. Cheu (Eds), Urban Disaster Mitigation: The Role of Engineering and Technology, Elsevier Science Ltd, 47-62.

Lee, C. M. W., Y. M. Cheng, and Y. Wang, 1978: Geology of the Taipei basin. Taiwan mining, 30, 350-380. (in Chinese)

Lee, S. J., D. Komatitsch, B. S. Huang, and J. Tromp, 2009: Effects of topography on seismic-wave propagation: An example from northern Taiwan. Bull. Seismol. Soc. Am., 99, 314-325, doi: 10.1785/0120080020. [Link]

Lermo, J. and F. J. Chavez-Garcia, 1993: Site effect evaluation using spectral ratios with only one station. Bull. Seismol. Soc. Am., 83, 1574-1594.

Loh, C. H., J. Y. Hwang, and T. C. Shin, 1998: Observed variation of earthquake motion across a basin - Taipei city. Earthq. Spectra, 14, 115-133, doi: 10.1193/1.1585991. [Link]

Loukachev, I., N. Pralle, and G. Gudehus, 2002: Dilatancyinduced $P$ waves as evidence for nonlinear soil behavior. Bull. Seismol. Soc. Am., 92, 854-862, doi: 10.1785/ 0120010115. [Link]

Mucciarelli, M., M. R. Gallipolli, and M. Arcieri, 2003: The stability of the horizontal-to-vertical spectral ratio of triggered noise and earthquake recordings. Bull. Seismol. Soc.
Am., 93, 1407-1412, doi: 10.1785/0120020213. [Link]

National Center for Research on Earthquake Engineering, Sino Geotechnology, Inc., The Geological Survey for Strong Motion Stations in Taiwan, Report, 2001-2004 (in Chinese).

Shieh, C. F., 1992: Estimation of Q value by SP/S spectral ratio. Terr. Atmos. Ocean. Sci., 3, 469-482.

Siddiqqi, J. and G. M. Atkinson, 2002: Ground-motion amplification at rock sites across Canada as determined from the horizontal-to-vertical component ratio. Bull. Seismol. Soc. Am., 92, 877-884, doi: 10.1785/0120010155. [Link]

Sokolov, V. Yu., 1998: Rough estimation of site response using earthquake ground motion records. In: Irikura, K., K. Kudo, H. Okada, and T. Sasatani (Eds), Proc. of the Second Int. Symp. on the Effects of Surface Geology on Seismic Motion, Yokogama, Japan, 1-3 December 1998, Balkema, Rotterdam, 517-522.

Sokolov, V. Yu. and Yu. K. Chernov, 2001: Probabilistic microzonation of the urban territories: A case of Tashkent city. Pure Appl. Geophys., 158, 2295-2311, doi: 10.1007/ PL00001171. [Link]

Sokolov, V. Yu. and W. Y. Jean, 2002: Ground motion characteristics in the Taipei basin from earthquakes of various locations. Struct. Eng., 17, 18-30. (in Chinese)

Sokolov, V. Yu., C. H. Loh, and K. L. Wen, 2000: Empirical study of sediment-filled basin response: A case of Taipei city. Earthq. Spectra, 16, 681-707, doi: 10.1193/1. 1586134. [Link]

Sokolov, V., C. H. Loh, and K. L. Wen, 2001: Site-dependent design input ground motion estimations for the Taipei area: A probabilistic approach. Probab. Eng. Mech., 16, 177191, doi: 10.1016/S0266-8920(00)00021-7. [Link]

Sokolov, V. Yu., C. H. Loh, and K. L. Wen, 2003: Evaluation of hard rock spectral models for the Taiwan region on the basis of the 1999 Chi-Chi earthquake data. Soil Dyn. Earthq. Eng., 23, 715-735, doi: 10.1016/S0267-7261(03) 00075-7. [Link]

Sokolov, V. Yu., C. H. Loh, and K. L. Wen, 2004: Evaluation of generalized site response functions for typical soil classes (B, C, and D) in the Taiwan region. Earthq. Spectra, 20, 1279-1316, doi: 10.1193/1.1814121. [Link]

Sokolov, V. Yu, K. P. Bonjer, M. Oncescu, and M. Rizescu, 2005a: Hard rock spectral models for intermediate-depth Vrancea, Romania, earthquakes. Bull. Seismol. Soc. Am., 95, 1749-1765, doi: 10.1785/0120050005. [Link]

Sokolov, V. Yu., C. H. Loh, and W. Y. Jean, 2005b: Analysis of peculiarities of strong ground motion excitation (source scaling) and propagation (attenuation) from earthquakes located in different source zones in Taiwan. Report R9402, Center for Earthquake Engineering Research, National Taiwan University, 136 pp.

Sokolov, V. Yu., C. H. Loh, and W. Y. Jean, 2006: Strong ground motion source scaling and attenuation models for earthquakes located in different source zones in Taiwan. Proc. of the $4^{\text {th }}$ International Conference on Earthquake Engineering, 12-13 October 2006, Taipei, Taiwan, CD- 
ROM, paper 03.

Sokolov, V. Yu., C. H. Loh, and W. Y. Jean, 2007: Application of horizontal-to-vertical (H/V) Fourier spectral ratio for analysis of site effect on rock (NEHRP-class B) sites in Taiwan. Soil Dyn. Earthq. Eng., 27, 314-323, doi: 10.1016/j.soildyn.2006.09.001. [Link]

Takahashi, K., S. Ohno, M. Takemura, T. Ohta, Y. Sugawara, T. Hatori, and S. Omote, 1992: Observation of earthquake strong-motion with deep borehole. Generation of vertical motion propagating in surface layers after $\mathrm{S}$ wave arrival. Proc. Tenth World Conf. on Earthq. Eng., Balkema, Rotterdam, 1245-1250.

Theodulidis, N. and P. Y. Bard, 1995: Horizontal to vertical spectral ratio and geological conditions: An analysis of strong motion data from Greece and Taiwan (SMART-1). Soil Dyn. Earthq. Eng., 14, 177-197, doi: 10.1016/02677261(94)00039-J. [Link]

Theodulidis, N., P. Y. Bard, R. Archuleta, and M. Bouchon, 1996: Horizontal-to-vertical spectral ratio and geological conditions: The case of Garner valley downhole array in southern California. Bull. Seismol. Soc. Am., 86, 306-319.

Tsai, C.-C. P., 1997: Relationships of seismic source scaling in the Taiwan region. Terr. Atmos.Ocean. Sci., 8, 49-68.

Wang, C. Y. and Y. H. Lee, 2002: An investigation of the basin structure in Taipei City. Proceeding of 2002 APEC Symposium on Confronting Urban Earthquakes/Seismic Early Warning, Nov. 28-29, Taipei, Taiwan, 137-148.

Wang, C. Y., W. C. Hsiao, and T. C. Sun, 1994: Reflection seismic stratigraphy in the Taipei basin (I) - Northestern Tai- pei. J. Geol. Soc. China, 37, 69-95.

Wang, C. Y., Y. H. Lee, and H. C. Chang, 1996: P- and S-wave velocity structures of the Taipei basin. Symposium on Taiwan strong motion instrumental program (II), Central Weather Bureau, 171-177.

Wang, C. Y., Y. H. Lee, M. L. Ger, and Y. L. Chen, 2004: Investigating subsurface structures and $\mathrm{P}$ - and $\mathrm{S}$-wave velocities in the Taipei basin. Terr. Atmos. Ocean. Sci., 15, 609-627.

Wang, J. H., 1988: Calculations of QS and QP using the spectral ratio method in the Taiwan area. Proceedings of the Geological Society of China 31, 81-89.

Wang, J. H., 1993: Q values of Taiwan: A review. J. Geol. Soc. China, 36, 15-24.

Wang, J. H., 2008: Urban seismology in the Taipei metropolitan area: review and prospective. Terr. Atmos. Ocean. Sci., 19, 213-233, doi: 10.3319/TAO.2008.19.3.213(T). [Link]

Wen, K. L. and H. Y. Peng, 1998a: Site effect analysis in the Taipei basin: Results from TSMIP network data. Terr. Atmos. Ocean. Sci., 9, 691-704.

Wen, K. L. and H. Y. Peng, 1998b: Strong ground motion observations in the Taipei basin. In: Irikura, K., K. Kudo, H. Okada, and T. Sasatani (Eds), Proc. of the Second Int. Symp. on the Effects of Surface Geology on Seismic Motion, Yokogama, Japan, 1-3 December 1998, Balkema, Rotterdam, 263-270.

Wen, K. L., H. Y. Peng, L. F. Liu, and T. C. Shin, 1995: Basin effects analysis from a dense strong motion observation network. Earthq. Eng. Struct. Dyn., 24, 1069-1083, doi: 10.1002/eqe.4290240803. [Link] 